\title{
Erratum: Community engagement in the Faculty of Health Science: A concept analysis
}

\section{Authors:}

Vistolina Nuuyoma ${ }^{1}$ (D)

Agnes Makhene ${ }^{1}$ (D)

Affiliations:

${ }^{1}$ Department of Nursing,

Faculty of Health Science,

University of Johannesburg,

Johannesburg, South Africa

Corresponding author:

Vistolina Nuuyoma,

vistolina.nuuyoma@gmail.com

Dates:

Published: 01 Dec. 2021

How to cite this correction: Nuuyoma, V. \& Makhene, A., 2021, 'Erratum: Community engagement in the Faculty of Health Science: A concept analysis', Health $S A$

Gesondheid 26(0), a1774.

https://doi.org/10.4102/

hsag.v26i0.1774

\section{Copyright:}

C 2021. The Authors.

Licensee: AOSIS. This work

is licensed under the

Creative Commons

Attribution License.

In the version of this article initially published, Nuuyoma, V. \& Makhene, A., 2020, 'Community engagement in the Faculty of Health Science: A concept analysis', Health SA Gesondheid 25(0), 1403. https://doi.org/10.4102/hsag.v25i0.1403, the article section was given incorrectly. The correct section should be Original Research instead of Review Article.

This correction does not alter the study's findings of significance or overall interpretation of the study's results. The publisher apologises for any inconvenience caused. 